\title{
Study on levee reinforcement using double sheet-piles with partition walls
}

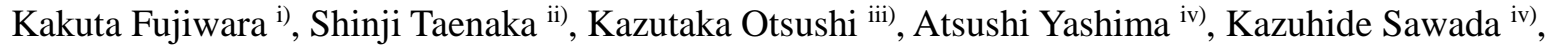 \\ Tatsuya Ogawa ${ }^{\text {v) }}$ and Kazuyoshi Takeda ${ }^{\text {v) }}$
}

\begin{abstract}
i) Steel Structures Research Lab., Nippon Steel \& Sumitomo Metal Corporation, 20-1, Shintomi, Futtsu-shi, Chiba, 293-8511, Japan. ii) Senior researcher, Steel Structures Research Lab., Nippon Steel \& Sumitomo Metal Corporation, 20-1, Shintomi, Futtsu-shi, Chiba, 293-8511, Japan.

iii) Senior manager, Construction Products Development Div., Nippon Steel \& Sumitomo Metal Corporation, 6-1, Marunouchi 2-chome, Chiyoda-ku, Tokyo, 100-8071, Japan.

iv) Professor, Faculty of Engineering, Gifu University, 1-1, Yanagido, Gifu-shi, Gifu, 501-1193, Japan.

v) Student, Faculty of Engineering, Gifu University, 1-1, Yanagido, Gifu-shi, Gifu, 501-1193, Japan.
\end{abstract}

\begin{abstract}
A large earthquake such as Nankai Trough Earthquake is concerned to occur in the near future and there is fear that coastal levees will sink by liquefaction. Authors proposed installing double sheet-piles into the levee and additionally combining another sheet-pile as a partition wall perpendicular to the extension direction to the levee. It has been confirmed by model tests that this countermeasure is very effective for the deformation/settlement reduction of levees during an earthquake. However, since the partition wall was modelled by the steel plate in the model tests, the effect of the joints between sheet-piles could not be taken into consideration. Authors also reproduced the model test results by using a two-dimensional effective stress analyses (code:LIQCA2D12) with high accuracy. In the numerical study, the slippage effect of joints between sheet-piles for the partition wall was taken into account. As a result, it was confirmed that the shear distortion generated between the joints weakens the constraint of the ground inside double sheet-piles, but in spite of this negative effect, the settlement of levee was reduced down to $15 \%$ compared to the case without countermeasure.
\end{abstract}

Keywords: levee reinforcement, sheet-pile, liquefaction, partition wall, shaking model test, numerical analysis

\section{INTRODUCTION}

A large earthquake of the scale as large as the 2011 Tohoku Region Pacific Coast earthquake is concerned to occur in the near future and there is fear that coastal levees will sink by liquefaction. As a countermeasure against the settlement of levees, the double sheet-piles installation method (Fig. 1) has been proposed and its effectiveness has been confirmed by model tests and numerical analyses. The more levee damage is reduced, the quicker it is feasible to recover the function of the levee, and as a result, personal and physical damages can be minimized. In this study, for the aim of further reduction of settlement of coastal levee, a fundamental study was carried out focusing on double sheet-pile walls with partition wall (Fig. 2(a)). Here, the partition wall is sheet-pile wall that is installed perpendicular to the double sheet-piles. In harbor quays, for instance, they are applied to coastal levees in practice and generally spaced every 10 sheet-piles $(9 \mathrm{~m}$ gap in the case of hat shaped steel sheet-piles).

In this study, firstly, we carried out shaking model tests using a steel plate as the model of partition wall.
Secondly, we reproduced the results of model tests in high accuracy using a two-dimensional effective stress
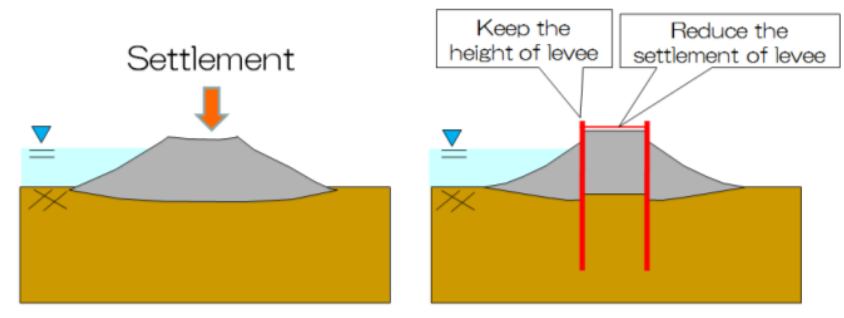

(a) Earthquake
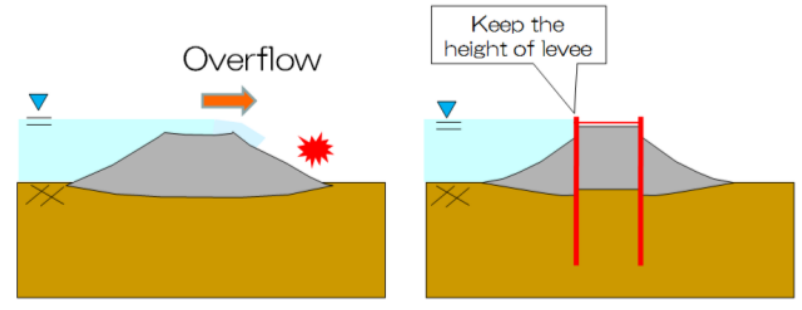

Fig.1. Effectiveness of double sheet-piles countermeasure 
analysis program, LIQCA2D12. However, in actual structures, the partition walls are steel sheet-pile wall. Therefore, the shear distortion is generated along the joints between sheet-piles when external force exerts in the perpendicular to the extension direction of levee (Fig. 2). Authors then modified 2-D analytical model in order to consider the joint of the partition wall and investigated the effect of the shear distortion using the modified model.

\section{EXPERIMENTAL STUDY}

\subsection{Test condition}

The shaking table model tests were carried out under the gravity field. The model ground consisted of a levee, liquefiable and unliquefiable layers. The height of the model levee is $300 \mathrm{~mm}$. That condition is approximately $1 / 25$ geometrical scale to the actual structure. As shown in Table 1, three cases: Case-A (without countermeasure), Case-B (with double sheet-piles), and Case-C (with double sheet-piles and partition wall), were examined. The ground and sheet-pile conditions are shown in Table 1. The model sheet-pile and partition wall were steel plates with thickness of $3.2 \mathrm{~mm}$ and $2.3 \mathrm{~mm}$, respectively based on the similarity rule. The tops of double sheet-piles were connected with tie-rods. The side of the partition wall was welded to double sheet-piles. The partition walls were installed at a gap of $340 \mathrm{~mm}$ perpendicular to the extension of levee direction (equal to approximately $9 \mathrm{~m}$ in an actual structure). The more detailed experimental conditions can be found in the literature.

The wave recorded at Kamaishi during the 2011 Tohoku Region Pacific Coast earthquake was adjusted as the input earthquake motion for shaking model tests, considering the similarity rule. In this study, input earthquake motion was modified by extending observed time duration three times in order to emphasize the effect of countermeasures (Fig. 4).

\subsection{Test result}

Deformed configuration of Case-C after shaking is shown in Fig. 3. While the foundation ground deformed due to liquefaction, the settlement of double sheet-piles themselves and the ground inside sheet-piles are significantly reduced. The settlements at two points along the extending direction of the levee are shown in Fig. 3 (C), and these both values were approximately $10 \mathrm{~mm}$. Therefore, the behavior of levee settlement was almost constant along extending direction. The time history of the settlement at the top of the levee in Cases-A C is shown in Fig. 4. The residual settlement in Case-C was $10 \%$ and $24 \%$ compared to Case-A and $B$ respectively. The very satisfactory settlement reduction effect was confirmed by the double sheet-piles with partition wall.

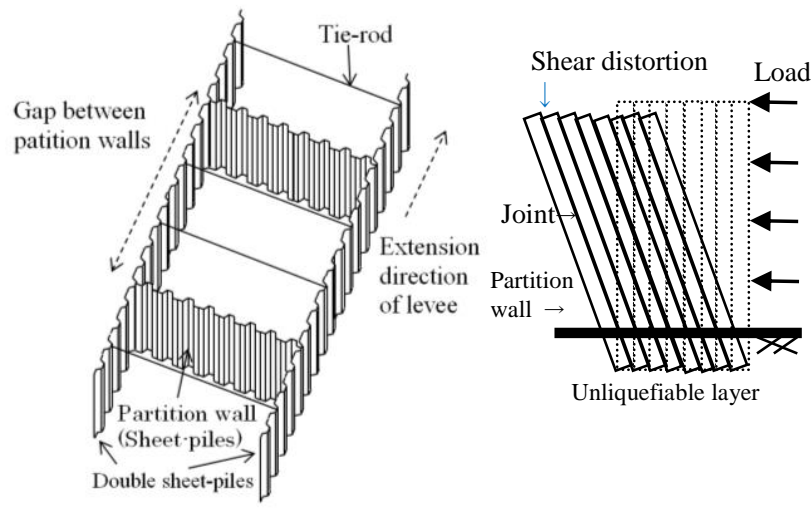

Fig.2. Partition wall
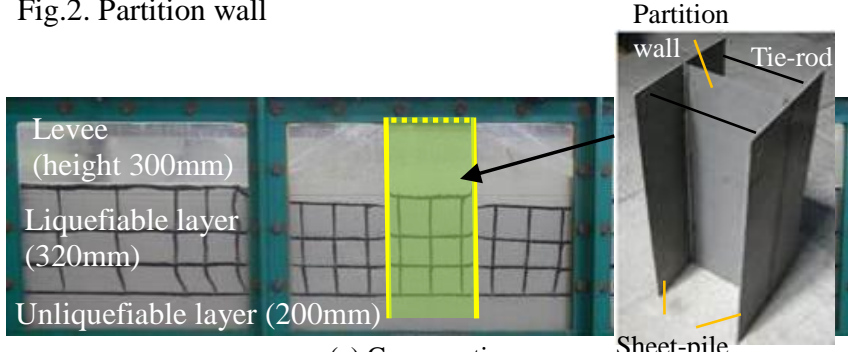

(a) Cross section

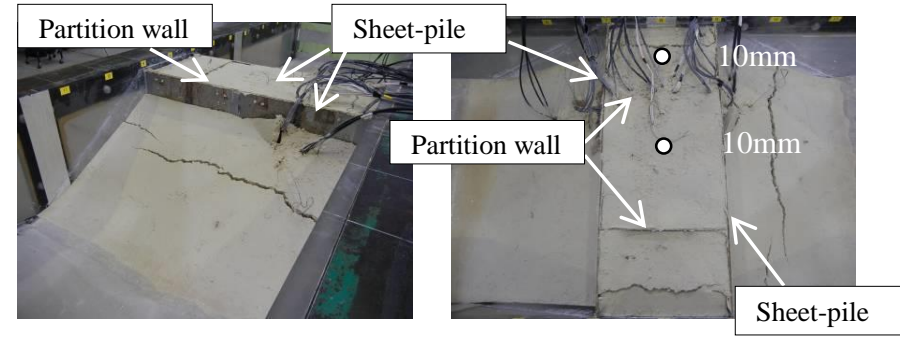

(b) Bird's-eye view

(c) Plain

Fig.3. Behavior of levee on shaking test (Case-C)

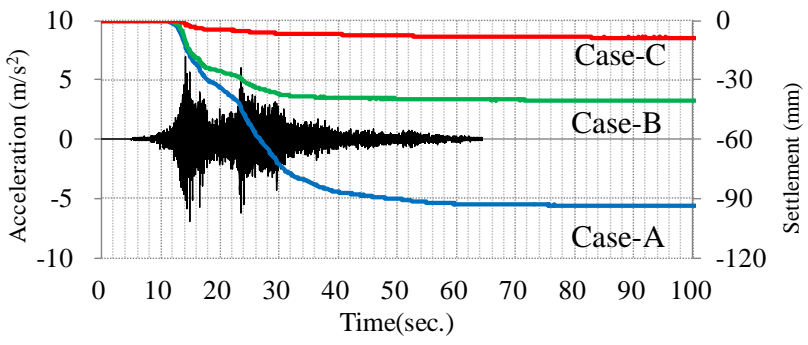

Fig.4. Input motion and settlement

Table.1. Soil conditions and countermeasures

\begin{tabular}{|c|c|c|c|c|c|c|c|c|c|c|c|c|}
\hline \multirow{3}{*}{$\begin{array}{c}\text { Test } \\
\text { cases }\end{array}$} & \multicolumn{7}{|c|}{ Soil conditions } & \multicolumn{5}{|c|}{ Countermeasures } \\
\hline & Levee & \multicolumn{3}{|c|}{ Liquefiable layer } & \multicolumn{3}{|c|}{ Unliquefiable layer } & \multicolumn{2}{|c|}{ Sheet-pile } & Tie-rod & \multicolumn{2}{|c|}{ Partition-wall } \\
\hline & $\gamma_{\mathrm{t}}\left(\mathrm{kN} / \mathrm{m}^{3}\right)$ & $\gamma_{\mathrm{t}}\left(\mathrm{kN} / \mathrm{m}^{3}\right)$ & $\mathrm{D}_{\mathrm{r}}(\%)$ & $\mathrm{k}(\mathrm{m} / \mathrm{sec})$ & $\gamma_{t}\left(\mathrm{kN} / \mathrm{m}^{3}\right)$ & $\mathrm{D}_{\mathrm{r}}(\%)$ & $\mathrm{k}(\mathrm{m} / \mathrm{sec})$ & $\mathrm{t}(\mathrm{mm})$ & $\mathrm{L}(\mathrm{mm})$ & $\phi(\mathrm{mm})$ & $\mathrm{t}(\mathrm{mm})$ & $\mathrm{L}(\mathrm{mm})$ \\
\hline Case-A & 16.2 & 19.1 & 42.4 & \multirow{3}{*}{$2.0 \times 10^{-5}$} & 19.9 & 91.4 & \multirow{3}{*}{$7.2 \times 10^{-6}$} & - & - & - & - & - \\
\hline Case-B & 15.6 & 19.0 & 43.2 & & 19.7 & 91.2 & & 3.2 & 720 & 4.0 & - & - \\
\hline Case-C & 16.0 & 19.1 & 44.4 & & 19.8 & 92.7 & & 3.2 & 720 & 4.0 & 2.3 & $7 \overline{20}$ \\
\hline
\end{tabular}




\section{NUMERICAL ANALYSIS FOR MODEL TEST}

\subsection{Conditions for analytical model}

The model tests were reproduced by using a two-dimensional effective stress analysis program, LIQCA2D12. The cross section of the numerical model is shown in Fig. 5. For more details such as boundary condition and the material parameters, refer to the literature.

In order to analyze 3-D structure using 2-D analysis, the partition wall was modeled by elastic planar elements and arranged so as to be superimposed on the ground elements inside double sheet-piles. The nodes on both side ends of the partition wall were put on the nodes of the sheet-piles in the same position and they were given equal displacement boundary conditions in the vertical and horizontal directions. The input values for the partition wall are shown in Table. 2. In the region inside double sheet-piles, the thickness of the partition wall and its interval were taken into consideration in 2-D analysis.

\subsection{Verification of reproduction precision}

For Case-C, the levee deformation with excess pore water pressure ratio distribution $(\mathrm{t}=80 \mathrm{sec}$.) is shown in Fig. 6. It is found that while the foundation ground deforms due to liquefaction, the settlement of double sheet-piles themselves and the ground inside sheet-piles are significantly reduced. In Cases $-\mathrm{A} \sim \mathrm{C}$, the time history of the settlement at the top of the levee is shown in Fig. 7. The settlement was greatly reduced in Case-C compared to that of other cases, and the results could be quantitatively reproduced in high accuracy, including Case-A and B. The time history of the excess pore water pressure at points P1 (Horizontal ground) and P2 (Beneath the levee) in Fig. 6 is shown in Fig. 8. While the water pressure at P2 in analysis was dissipated faster than experimental one, the water pressure could be successfully reproduced in P1 and P2. The residual deformation of the sheet-piles is shown in Fig. 9. It is found that the bending deformation takes place toward outside in Case-B. On the other hand, no deformation occurred in Case-C. In Case- $\mathrm{C}$, the increase in the volume inside double sheet-piles were limited by the partition wall effect, and this is contributed to reduce the settlement at the top of the levee.

From the above results, even 3-D structure with discretely installed partition walls could be successfully reproduced by using a 2-D analysis model. This is because the levee generally behaved invariably along the extension direction of the levee, which was observed in model test. It is assumed that 3-D analysis model is required when the interval between partition walls becomes longer than that in the model tests $(9 \mathrm{~m}$ in actual size) because bending deformation of sheet-piles must be considered in the section (Section A) away from the partition wall, as shown in Fig. 10.
Table.2. Parameters for partition wall

\begin{tabular}{l|c||c}
\hline Young's modulus $\left(\mathrm{kN} / \mathrm{m}^{2}\right)$ & $E$ & $2.0 \times 10^{8}$ \\
\hline Shear stiffness $\left(\mathrm{kN} / \mathrm{m}^{2}\right)$ & $G$ & $7.8 \times 10^{7}$ \\
\hline Thickness $(\mathrm{m})$ & $t$ & $6.6 \times 10^{-3}$ \\
\hline Density $\left(\mathrm{t} / \mathrm{m}^{2}\right)$ & $\rho$ & 7.8 \\
\hline
\end{tabular}

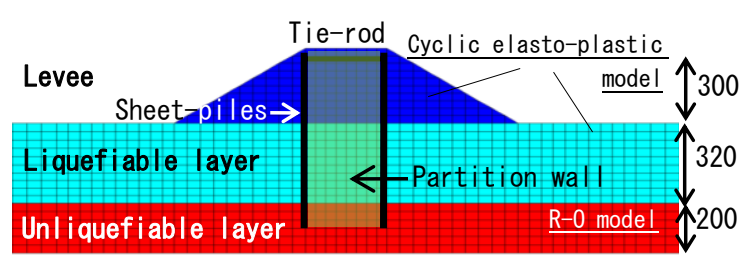

Fig.5. Numerical model

[Unit:mm]

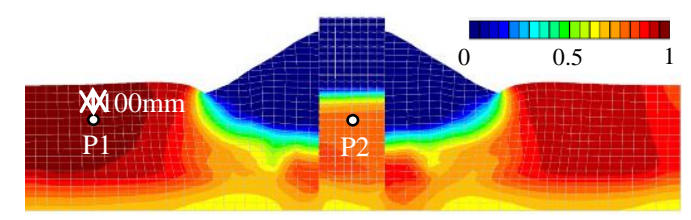

Fig.6. Levee deformation with excess

pore water pressure ratio distribution

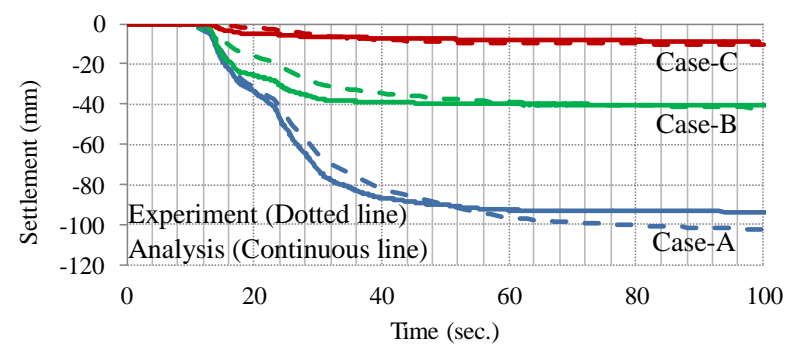

Fig.7. Settlemet at top of the levee

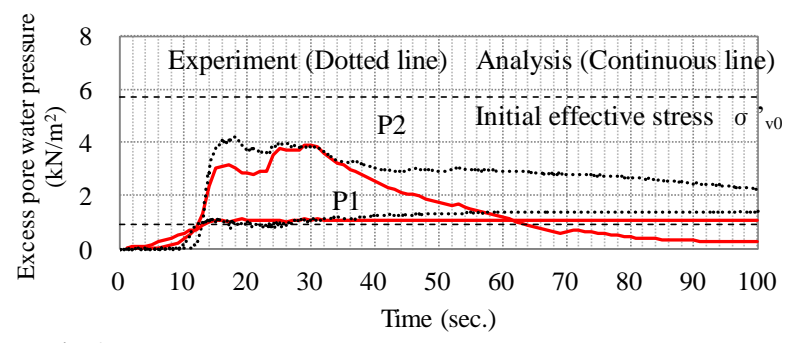

Fig.8. Excess pore water pressure

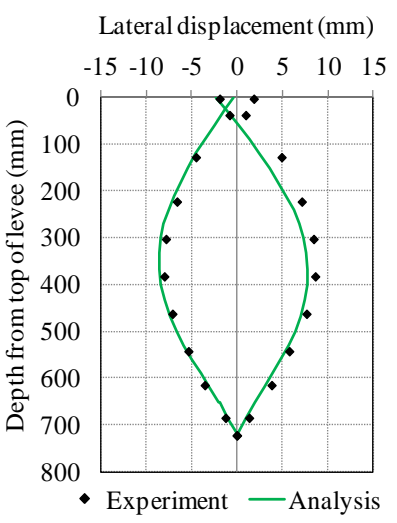

(a) Case-B

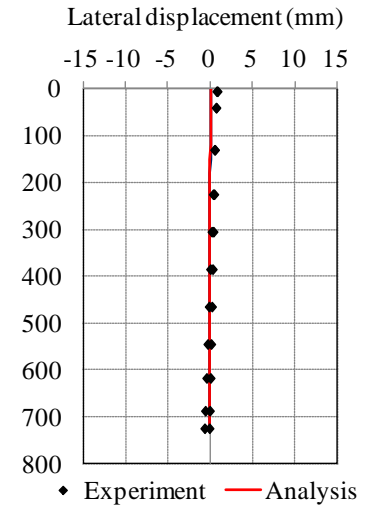

(b) Case-C
Fig.9. Deformation of sheet-piles 


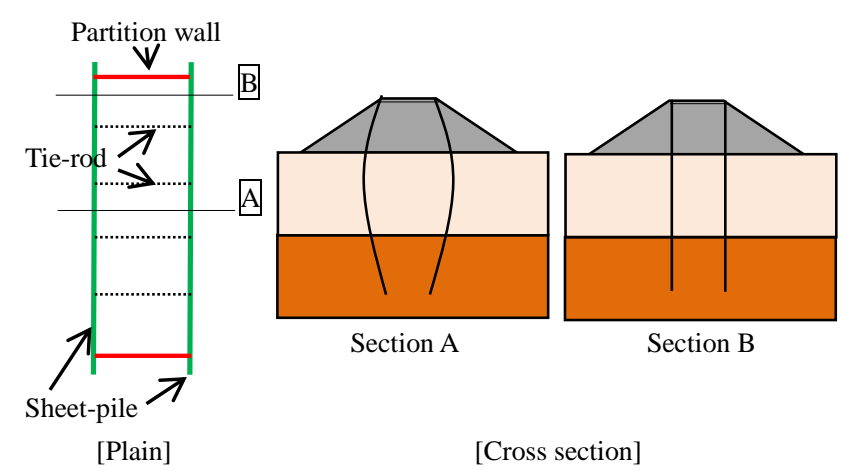

Fig.10. Conceptual diagram of sheet-pile due to interval of partition wall

\section{EXAMINATION BY CONSIDERING THE PARTITION WALL JOINTS}

\subsection{Numerical model for joints}

In the previous chapter, the partition walls were examined under the condition that they are made of steel plates without any joints. In actual structures, as the partition wall is a sheet-pile wall with joints, shear distortion is generated during an earthquake (Fig. 2). The effect of shear distortion on the behavior of the levee and effectiveness of countermeasures are investigated in this chapter based on the numerical model used in the previous chapter.

The numerical model (Case-D) with the joints of the partition wall is shown in Fig. 11. In order to take the joints into consideration, the partition wall was segmented into 8 strip-like pieces. One sheet of strip-like partition wall had a width of $45 \mathrm{~mm}$, which represents $875 \mathrm{~mm}$ when scaled up to actual side. This is approximately equal the $900 \mathrm{~mm}$ effective width of hat shaped steel sheet-piles. As shown in Fig. 11, the adjacent elements of the stripped partition wall were connected by joint elements. The rigidity of the joint elements in the normal direction $(\mathrm{kn})$ is very high not to allow relative displacement. On the other hand, in order to model a smooth displacement in the shear direction, the rigidity of joint elements in shear direction is very low.

\subsection{Numerical result}

The numerical results of the partition wall after shaking are shown in Fig. 12. Fig. 12(a) shows the results of the top nodes extracted from the partition wall (Deformation magnification of 1.0). The shear distortion of the joints generated in Case-D can be seen. Fig. 12(b) shows the overall of the deformation of the partition wall (Deformation magnification of 30). The rotational behavior can be found in Case-C. In contrast, little rotation can be found in Case-D. Fig. 12(c) shows the contour of the shear strain of the partition wall. While shear strain can be found in Case-C, no shear strain can be found in Case-D due to the shear

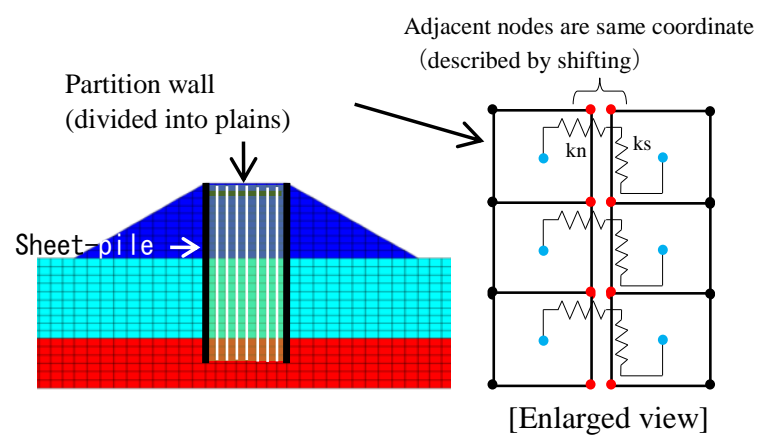

Fig.11. Numerical model (Case-D)

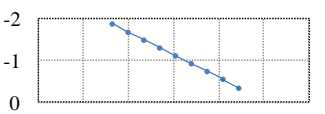

Case-C

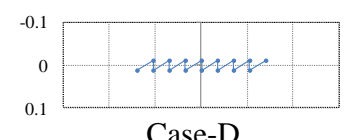

Case-D

(a) Top node (Deformation magnification 1.0)
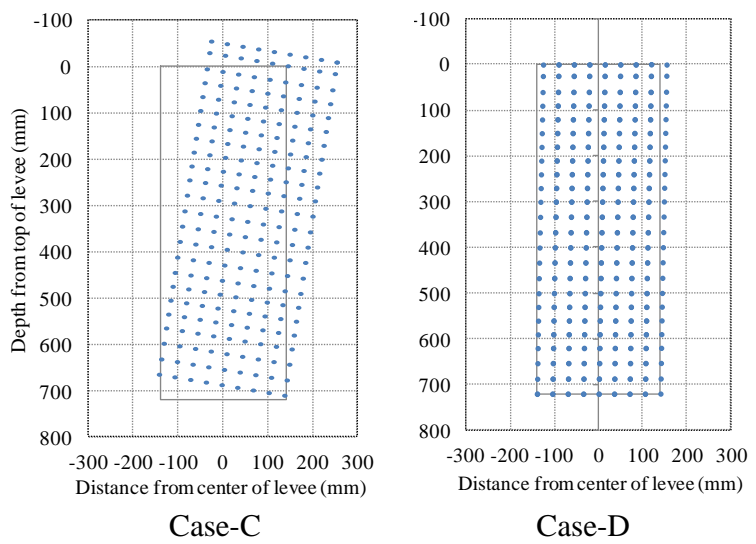

(b) Overall (Deformation magnification 30)

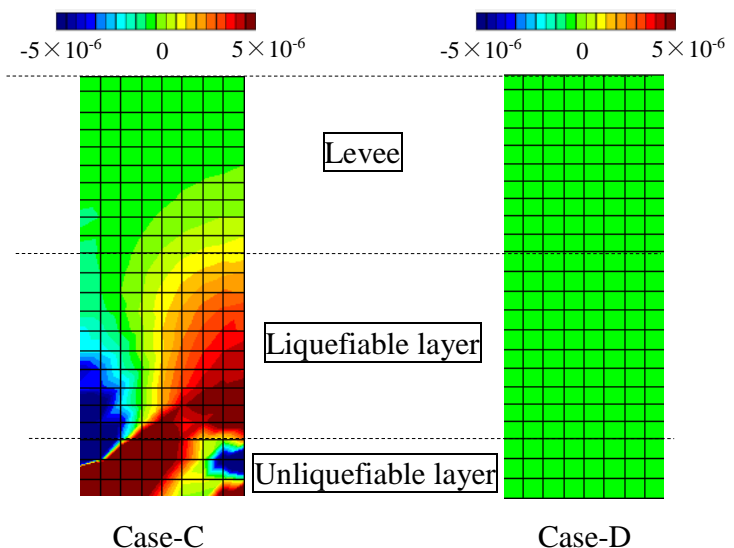

(c) Shear strain

Fig.12. Result of partition wall (residual state)

Table.3. Average shear strain of liquefiable layer between double sheet-piles (residual state)

\begin{tabular}{cc}
\hline Case-C & Case-D \\
\hline 1.14 & 1.75 \\
\hline
\end{tabular}


distortion of joints. The average shear strain (residual value) in the liquefiable layer is shown in Table 3. The shear strain was larger in Case-D than in Case-C. This is possibly due to the fact that the shear distortion between joints weakens the constraint of the ground inside double sheet-piles. The time history of the settlement at the top of the levee and that of the excess pore water pressure at point P2 (Beneath the levee) are shown in Fig. 13 and Fig. 14, respectively. The settlement displacement and excess pore-water pressure becomes larger in Case-D compared to Case-C. The settlement increased as the increase in the shear strain of the ground inside of double sheet-piles with higher excess pore water pressure. Meanwhile, the settlement was $15 \%$ compared to the case without countermeasure (Case-A). The significant settlement reduction effect was confirmed. Moreover, although friction between joints along the shear direction was postulated to be very small in this analysis, shear friction also works between the joints of sheet-piles in actual structures. It is considered that the actual behavior exists between that in Case-C and Case-D.

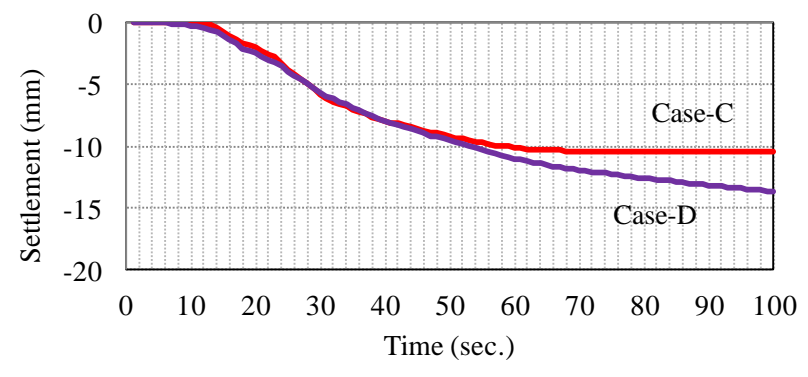

Fig.14. Settlement at top of the levee

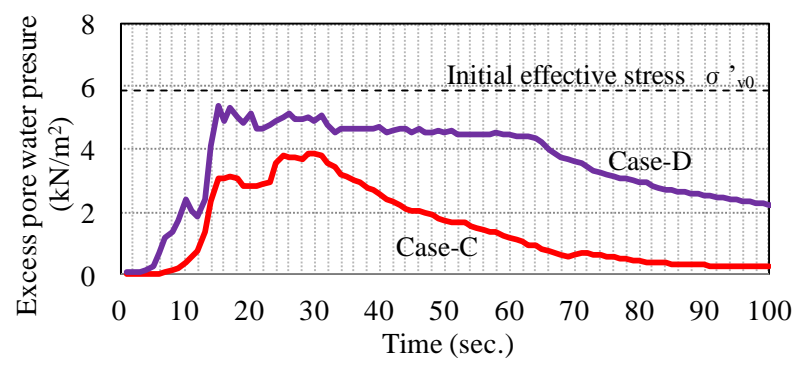

Fig.13. Excess pore water pressure at $\mathrm{P} 2$

\section{CONCLUSIONS}

Authors investigated the effect of double sheet-piles with partition wall as coastal levee reinforcement method. The following conclusions were obtained by carrying out shaking table model tests and 2-D numerical analyses (code:LIQCA2D12) under the gravity field.

1) It was confirmed through the model tests that the double sheet-piles with partition wall significantly reduced levee settlement down to approximately $10 \%$ compared to the case without countermeasure.

2) It was confirmed that even 3-D structures can be successfully reproduced by using a 2-D analysis model of superimposed planar elements for the partition wall and the ground, as long as the interval between partition walls is limited to around the current service value $(9 \mathrm{~m}$ in the case of hat shaped steel sheet-piles).

3) As the partition walls in actual structures are sheet-pile walls with joints, authors modified the numerical model in order to take the effect of joint into consideration. As a result, it was confirmed that the shear distortion generated between the joints increased the shear distortion of the ground inside double sheet-piles and excess pore water pressure. However, compared to the case without countermeasure, the settlement is reduced down to approximately $15 \%$, indicating significant settlement reduction effect.

4) The influence of the interval of partition walls was discussed in the framework of 2-D analysis. The limitation of the 2-D analysis will be avoided by carrying out 3-D analysis in the near feature.

\section{REFERENCES}

1) Fujiwara, K., Koseki, J., Otsushi, K., Nakayama, H. (2013) : Study on reinforcement method of levees using steel sheet-piles, Foundation and Soft Ground Engineering Challenges in Mekong Delta, Ho Chi Minh, Vietnam, 281-289.

2) Iai, S. (1988) : Similitude for shaking table tests on soil-structure-fluid model in $1 \mathrm{~g}$ gravitational field, Report of the port and harbor research institute, Vol.27, No.3, 3-24

3) Kobori, Y., Noda, S., Sawada, K., Yashima, A., Fuziwara, K., Otsushi, K. (2014) : Study on a reinforcement method for coastal dykes against huge earthquakes (2. Numerical analysis) , $49^{\text {th }}$ Japan National Conference on Geotechnical Engineering, Kitakyushu, Japan. (In Japanese)

4) Kort, D, A. (2002): Steel Sheet Pile Walls in Soft Soil, ISBN 90-407-2276-5, DUP Science, 90-91

5) LIQCA Liquefaction Geo-Research Institute (LIQCARI) (2012) : LIQCA2D12 • LIQCA3D11.

6) Noda, S., Kobori, Y., Sawada, K., Yashima, A., Fuziwara, K., Otsushi, K. (2014) : Study on a reinforcement method for coastal dykes against huge earthquakes (1. Shaking table tests), $49^{\text {th }}$ Japan National Conference on Geotechnical Engineering, Kitakyushu, Japan. (In Japanese)

7) Ohori, K., Shoji, Y., Takahashi, K., Ueda, H., Hara, M., Kawai, Y., Shiota, K. (1984) : Stability Behavior of double sheet Pile wall Structure, Report of the port and harbor research institute, Vol.23, No.1, 103-152.

8) Oka, F., Yoshida, N., Kai, S., Tobita, T., Higo, Y., Torii, N., Kagamihara, S., Nakanishi, N., Kimoto, S., Yamakawa, Y., Touse, Y., Uzuoka, R., Kyoya, T. (2012) : Reconnaissance Report of Geotechnical Damage due to the 2011 off the Pacific coast of Tohoku Earthquake - Northern Area of Miyagi Prefecture -, Japanese Geotechnical Journal, Vol.7, No.1, 37-55.

9) Otsushi, K., Koseki, J., Kaneko, M., Tanaka, H., Nagao, N., (2011) : Experimental study on reinforcement method of levees by sheet-pile, Geotechnical Journal, Vol.6, No.1, $1-14$. 